\title{
POLINIZAÇÃO ARTIFICIAL DA ATEMÓIA COM DIVERSAS FONTES DE PÓLEN COMPARADA COM A NATURAL ${ }^{(1)}$
}

\author{
MARCELO ROSA MELO ${ }^{(2,5)}$; CELSO VALDEVINO POMMER ${ }^{(3,6)}$; \\ RYOSUKE KAVATI ${ }^{(4)}$
}

\begin{abstract}
RESUMO
Para estudar a polinização da atemóia (Annona squamosa L. x A. cherimola) e determinar a técnica de polinização que produz frutos em maior quantidade e melhor qualidade, montou-se um experimento de polinização. O experimento foi realizado com a cultivar Gefner, no período de novembro de 2000 a março de 2001, em pomar comercial, localizado em Lins (SP), a 424 metros de altitude. As plantas apresentavam 13 anos de idade. Empregou-se o delineamento de blocos ao acaso, com cinco tratamentos e seis repetições. Os tratamentos foram os seguintes: 1) polinização manual (pólen de A. squamosa L.); 2) polinização manual (pólen da atemóia cultivar Gefner); 3) polinização manual (pólen da atemóia cultivar African Pride); 4) polinização manual (pólen da atemóia cultivar PR-3); 5) polinização natural ou aberta. A avaliação do vingamento dos frutos ocorreu dez dias após a polinização e da quantidade dos frutos com conformação perfeita ou defeituosa, aos 40 dias. Os frutos foram colhidos 120 dias após a polinização e pesados individualmente. Amostraram-se, também, três frutos para as seguintes determinações: massa de sementes e da polpa, número de sementes por 100 gramas de polpa, teor de sólidos solúveis totais, acidez total e relação sólidos solúveis/acidez. Para a atemóia, a polinização com pólen de A. squamosa L. foi mais efetiva, aumentando o vingamento de frutos $(80,5 \%$, comparado com outros quatro tratamentos, que foi menos de $22 \%$ ), a produção e a porcentagem de frutos perfeitos.
\end{abstract}

Palavras-chave: atemóia, anonáceas, polinização artificial e natural, fontes de pólen.

\section{ABSTRACT \\ NATURAL AND ARTIFICIAL POLLINATION OF ATEMOYA IN BRAZIL}

An experiment was carried out to study atemoya pollination and to determine the pollination method that produces fruits in larger amount and quality. The experiment was accomplished with cultivar Gefner, in the period of November 2000 to March 2001, in a commercial orchard located in the county of Lins - SP, at an altitude of 424 meters. The plants were 13 years old. The experimental design was in randomized blocks, with 5 treatments and 6 replicates. The treatments were as follows: 1) hand pollination (pollen of A. squamosa L.); 2) hand pollination (pollen of atemoya cultivar Gefner); 3) hand pollination (pollen of atemoya cultivar African Pride); 4) hand pollination (pollen of atemoya cultivar PR-3); 5) natural (open) pollination. The evaluation of fruit set happened 10 days after the pollination and the amount of fruits with perfect or defective shape after 40 days. Atemoya fruits were picked 120 days after the pollination and individually weighed. 3-fruit samples of each treatment were taken, for the following determinations: seed and pulp weigh, number of seeds per $100 \mathrm{~g}$ of pulp, total soluble solids content, total acidity and soluble solids/acidity ratio. The pollination of atemoya with pollen of $A$. squamosa L. was more effective, increasing the fruit set $(80.5 \%$ compared to less than $22 \%$ in the other treatments), fruit production and percentage of perfect fruits.

Key words: atemoya, hand pollination, natural pollination, pollen source.

${ }^{1}$ ) Recebido para publicação em 21 de março e aceito em 26 de agosto de 2002.

$\left({ }^{2}\right)$ Mestre em Agricultura Tropical e Subtropical, área de concentração em Tecnologia de Produção Agrícola, Instituto Agronômico (IAC), Caixa Postal 28, 13001-970 Campinas (SP). E-mail: rosamelo1@yahoo.com

$\left(^{3}\right)$ Centro Avançado de Pesquisa Tecnológica do Agronegócios de Frutas, IAC, Caixa Postal 11, $13200-970$ Jundiaí (SP). E-mail: pommer@iac.br

(4) Coordenadoria de Assistência Técnica Integral (CATI), Lins (SP). E-mail: edr.lins@cati.sp.gov.br

$\left({ }^{5}\right)$ Bolsista da Fapesp.

$\left({ }^{6}\right)$ Com bolsa de produtividade científica do CNPq. 


\section{INTRODUÇÃO}

Escolheu-se estudar a atemóia, por se tratar de fruta muito saborosa com boa potencialidade econômica de cultivo no Brasil (especialmente para pequenos produtores). Estima-se que sejam cultivados 10.000 ha de anonáceas no Brasil (CARMO, 2000), dos quais 1.000 ha correspondem à atemóia, distribuídos em, aproximadamente, 500 ha na região Nordeste do país e 500 ha no Sudeste brasileiro. A cultura de atemóia, um híbrido entre $A$. squamosa $\mathrm{L}$. (fruta-do-conde ou ata) e A. cherimola Mill. (cherimóia), proporciona boa remuneração ao produtor, pois o preço de uma caixa com oito frutos de 450 g pode alcançar $R \$ 15,00$. Uma planta adulta, manejada adequadamente, pode produzir até 20 caixas de frutos de boa qualidade (ToKUnAGA, 2000).

A produtividade da atemóia, porém, é baixa, devido à escassez de informações a respeito dos tratos culturais, além da polinização natural deficiente, pela ocorrência da dicogamia protogínica. Esse fenômeno se deve à falta de sincronia no amadurecimento dos órgãos florais feminino e masculino dessas fruteiras.

Para incrementar a produtividade, Schroeder citado por RICHARDSON e ANDERSON (1996) propôs, para as condições da Califórnia - EUA, o emprego da polinização artificial ou manual. A polinização artificial apresenta a vantagem de produzir frutos em maior quantidade, de maior tamanho e de melhor formato. Com seu uso, pode-se aproveitar melhor a primeira florada, manejar e escalonar a colheita dos frutos, polinizando as flores das partes mais baixas da planta (Guirado, 1992). Por outro lado, essa operação eleva os custos de produção da cultura; para se obter produtividade de $10 \mathrm{Mg} \cdot \mathrm{ha}^{-1}$, são necessárias duzentas horas de trabalho para polinizar um hectare (FArré e Hermoso, 1997).

A polinização artificial pode apresentar resultados diferentes, dependendo da cultivar fornecedora do pólen. Schwarzenberg citado por GARDIAZABAL e ROSENBERG (1993) realizou experimento de polinização em 1946 e comprovou que o uso de pólen das mesmas cultivares de cherimóia apresentou resultados de vingamento de frutos superiores ao pólen oriundo de cultivares diferentes. Saint Marie citado por Gardiazabal e RosenberG (1993) constatou que o emprego do pólen da cultivar Bronceada apresentou resultados superiores ao do pólen de 'Santa Júlia', quando polinizados em cultivares distintas. Duarte e Escobar (1997) polinizaram a cultivar Cumbe de cherimóia e observaram que polens da cultivar Bronceada e
Cumbe apresentaram resultados superiores aos da atemóia cultivar Gefner.

KAVATI et al. (1997), com o objetivo de aumentar a frutificação de atemóia e melhorar o formato dos frutos, demonstraram a necessidade da realização de mais estudos sobre a polinização.

O presente trabalho visou comparar distintas maneiras de polinizar a atemóia nas condições climáticas paulistas e verificar quais as fontes de pólen que poderiam promover maior vingamento dos frutos de atemóia e os efeitos da polinização na quantidade e qualidade dos frutos produzidos.

\section{MATERIAL E MÉTODOS}

O experimento foi realizado em propriedade situada em Lins (SP), à altitude de 425 metros, com as seguintes coordenadas geográficas: $21^{\circ} 40^{\prime} \mathrm{S}$ e $49^{\circ} 45^{\prime} \mathrm{W}$. O clima é do tipo Aw, com temperatura média anual estimada em $23^{\circ} \mathrm{C}$ e precipitação média anual de $1.239 \mathrm{~mm}$, com chuvas concentradas no verão. O solo da área experimental foi classificado como Argissolo Vermelho-Amarelo. O pomar foi composto por 350 plantas de atemóia, com 13 anos de idade, predominando a cultivar Gefner.

Avaliaram-se os frutos a partir do início de novembro de 2000 até o final de março de 2001. Durante o período experimental, as plantas receberam os mesmos tratos culturais (adubação, controle fitossanitário, capina, irrigação) utilizados pelo agricultor. O tratamento fitossanitário foi realizado com intervalo de três dias, antes e após a polinização. O delineamento experimental empregado foi o de blocos ao acaso (DBC). As plantas selecionadas de atemóia cv. Gefner receberam os cinco tratamentos, em seis repetições. Os tratamentos aplicados foram os seguintes:

1. Polinização manual (pólen de A. squamosa L.);

2. Polinização manual (pólen da mesma cultivar);

3. Polinização manual (pólen de atemóia cultivar African Pride);

4. Polinização manual (pólen de atemóia cultivar PR-3);

5. Polinização natural ou aberta.

Foram escolhidas 30 plantas com idade e vigor semelhantes e utilizadas 18 flores por tratamento em cada bloco para constituir uma parcela. Aplicaram-se os cinco tratamentos em cada planta de atemóia cv. Gefner. A polinização iniciou-se às $6 \mathrm{~h} 30 \mathrm{~min}$ e encerrou-se às $10 \mathrm{~h} \mathrm{de} 1^{\circ} / 11 / 2000$. As flores não foram ensacadas. Marcaram-se as flores que receberam os tratamentos, na altura do pedúnculo, no instante da polinização, com fitas de plástico colorido. 
Para obtenção do pólen adotou-se o método, adaptado de Guirado (1992), que consistiu do seguinte: a partir das $15 \mathrm{~h}$, colheu-se, aleatoriamente, número de flores igual ao número que seria polinizado na manhã seguinte, as quais se encontravam em antese, no estádio fêmea (que ainda não tivessem passado para o estádio macho). Colheram-se, preferencialmente, flores surgidas em ramo de um ano, pois estas não frutificam bem, mas são boas fornecedoras de pólen. Dessa forma, procurou-se interferir o menos possível no potencial produtivo das plantas. As flores colhidas foram colocadas em bandejas plásticas e cobertas com outra bandeja. Levadas ao galpão, foram distribuídas em camada única em pratos plásticos para evitar fermentação do pólen e mantidas em condições ambientais naturais. Na manhã seguinte, às 6 horas, as flores foram levadas para o campo e mantidas em caixa de papelão com tampa. Conforme a necessidade, extraiu-se o pólen das flores com os dedos. A seguir, com o auxílio de um pincel, o pólen foi agrupado e colocado em aplicador apropriado. Depois, introduziu-se a canícula do aplicador entre as pétalas até aproximar-se do estigma de cada flor, fazendo-se duplo bombeamento para assegurar boa polinização. Antes de cada polinização, o aplicador foi agitado em movimentos verticais para soltar o pólen aderido no fundo do recipiente. Terminada a operação, marcou-se a flor polinizada com tira de plástico colorido.

Os parâmetros ou variáveis estudados foram avaliados da seguinte maneira:

\section{a) Antes da colheita}

- Porcentagem de vingamento de frutos: dez dias após a polinização, efetuou-se a contagem do número de frutos vingados e calculou-se a porcentagem de vingamento.

- Porcentagem de frutos perfeitos: aos quarenta dias após a polinização, foram contados os frutos com contornos perfeitos e imperfeitos e determinada a porcentagem de frutos perfeitos.

\section{b) Após a colheita}

- Porcentagem final de frutos colhidos: na colheita, contou-se o número de frutos e determinou-se a porcentagem de frutos colhidos em relação aos vingados.

- Massa dos frutos colhidos: os frutos colhidos foram pesados logo após a colheita com o auxílio de uma balança com precisão de 0,1 grama.

- Produção total: estimada pela porcentagem de frutos vingados e a massa fresca média.
Para as avaliações a seguir, foram amostrados, sempre que possível, três frutos por planta.

- Massa de polpa: pesou-se a polpa dos frutos provenientes da amostra.

- Massa das sementes: as sementes de cada um dos frutos amostrados foram pesadas.

- Número de sementes por 100 gramas de polpa: as sementes de cada fruto amostrado foram contadas; posteriormente, calculou-se sua relação com 100 gramas de polpa.

- Sólidos solúveis totais: os teores de sólidos solúveis totais foram medidos com refratômetro de mesa e expressos em ${ }^{\circ}$ Brix.

- Acidez total titulável e pH: a acidez total foi determinada por titulometria, expressa em porcentagem, e o $\mathrm{pH}$, com o auxílio de um determinador de $\mathrm{pH}$.

- Relação entre sólidos solúveis totais e acidez total titulável.

\section{RESULTADOS E DISCUSSÃO}

Considerando a influência das condições ambientais sobre o sucesso da polinização, efetuaram-se observações sobre temperatura e chuva registradas antes e depois do período de polinização (Quadro 1). Observa-se que a faixa de temperatura no período foi elevada, o que não favoreceu a polinização. As chuvas em nada contribuíram para aumentar a umidade do ar.

No quadro 2, verifica-se que a polinização com pólen de $A$. squamosa L. mostrou-se mais eficiente que as demais no aumento da porcentagem de frutos vingados, o que confirma as observações dos agricultores locais, podendo ser utilizada com vantagem em relação à polinização com o pólen de outras cultivares. A porcentagem de vingamento, usando-se pólen de Gefner, esteve na mesma ordem de grandeza dos resultados obtidos por DUARTE et al. (1999), que verificaram $13,79 \%$ de vingamento utilizando pólen de atemóia 'Gefner' e 4,91\% para o controle. Em outro experimento em Honduras, esses autores observaram $0,0 \%$ de vingamento para o controle. Os resultados superiores, obtidos com pólen de A. squamosa L., poderiam ser explicados pelo menor tamanho dos grãos e pela maior quantidade de grãos de pólen que seriam pulverizados em cada aplicação de polinização(5). Entretanto, há necessidade de mais estudos para determinar os fatores que levaram a esses resultados, como viabilidade, conservação e germinação do pólen. A porcentagem de frutos vingados poderia ser melhor

$\left(^{5}\right)$ Engenheiro Agrônomo Ryosuke Kavati, comunicação pessoal. 
Quadro 1. Temperatura e precipitação observadas no período anterior e posterior à polinização de flores de atemóia. Lins (SP), 2000

\begin{tabular}{cccc}
\hline Datas & Temperatura mínima & Temperatura máxima & Precipitação \\
\hline & ${ }^{\circ} \mathrm{C}$ & ${ }^{\circ} \mathrm{C}$ & $\mathrm{mm}$ \\
$27 / 10$ & 27,0 & 22,0 & 0,0 \\
$28 / 10$ & 28,0 & 17,0 & 15,9 \\
$29 / 10$ & 31,0 & 17,0 & 0,0 \\
$30 / 10$ & 31,0 & 19,0 & 0,0 \\
$31 / 10$ & 30,0 & 18,0 & 0,0 \\
$1^{\circ} / 11$ & 37,0 & 22,0 & 0,0 \\
$2 / 11$ & 36,0 & 22,0 & 0,0 \\
$3 / 11$ & 37,0 & 22,0 & 0,0 \\
$4 / 11$ & 38,0 & 23,0 & 0,0 \\
$5 / 11$ & 34,0 & 23,0 & 0,0 \\
$6 / 11$ & 34,0 & 22,0 & 0,0 \\
\hline
\end{tabular}

caso as temperaturas fossem mais amenas (Quadro 1), à semelhança do que ocorre com a cherimóia.

O tratamento 1 (polinização com pólen de fruta-do-conde) foi superior aos demais na produção total colhida (Quadro 2). A massa fresca média dos frutos do tratamento 1 foi de 385 gramas, valor considerado bom para comercialização (KAVATI, 1992) e se assemelha ao valor médio encontrado por GEORGE et al. (1997) para a cultivar Gefner, que foi de 350 gramas. O peso dos frutos dos demais tratamentos foi inferior a 300 gramas. Na comercialização são considerados frutos pequenos.

Examinando os dados do quadro 3, percebe-se que o tratamento 1 (polinização com pólen de fruta-do-conde) foi superior aos demais, indicando a importância do emprego da prática de polinização artificial com essa fonte de pólen para a obtenção de maior quantidade de frutos comercializáveis (perfeitos).

A determinação do número médio de sementes por fruto foi prejudicada devido ao descarte de frutos antes da colheita provocado pelo ataque intenso da broca dos frutos Cerconota anonella. Os índices de número de sementes por $100 \mathrm{~g}$ de polpa foram todos superiores ao valor 10 (Quadro 4) que é o máximo aceito para o programa de melhoramento australiano de atemóia (GEORGE e BROADLEY, 1999) e diferiu do número encontrado por GEORGE et al. (1997), que encontraram 14,5 sementes por $100 \mathrm{~g}$ de polpa. Essa característica pode ser inerente à cultivar.

Verificou-se que o teor de sólidos solúveis variou de $19,6^{\circ}$ a $23,8^{\circ}$ Brix, valores aceitáveis, segundo o padrão australiano, que determina frutos aceitáveis acima de $18^{\circ}$ Brix (SCHELDEMAN e VAN DAMME, 1999). A relação SST/ATT ótima não é conhecida (Quadro 5).

Quadro 2. Efeito do modo de polinização e do pólen sobre o número médio de frutos vingados, porcentagem de frutos vingados, produção total e massa fresca média de atemóia cv. Gefner. Lins (SP), 2000

\begin{tabular}{lcccc}
\hline \multicolumn{1}{c}{ Tratamento } & $\begin{array}{c}\text { Fruto } \\
\text { vingado }\end{array}$ & $\begin{array}{c}\text { Fruto } \\
\text { vingado }\end{array}$ & $\begin{array}{c}\text { Produção } \\
\text { total } \\
\text { colhida }\end{array}$ & $\begin{array}{c}\text { Massa } \\
\text { fresca } \\
\text { média }\end{array}$ \\
\hline 1. Polinização manual (pólen de A. squamosa L.) & $\mathrm{n}^{\mathrm{o}}$ médio & \% & $\mathrm{kg}$ & $\mathrm{g}$ \\
2. Polinização manual (pólen da mesma cultivar) & $14,5 \mathrm{a}$ & $80,5 \mathrm{a}$ & $10.805,76 \mathrm{a}$ & 385,92 \\
3. Polinização manual (pólen da atemóia African Pride) & $3,8 \mathrm{~b}$ & $21,3 \mathrm{~b}$ & $956,32 \mathrm{~b}$ & 239,08 \\
4. Polinização manual (pólen da atemóia PR-3) & $2,3 \mathrm{~b}$ & $13,0 \mathrm{~b}$ & $252,87 \mathrm{~b}$ & 252,87 \\
5. Polinização natural ou aberta & $0,3 \mathrm{~b}$ & $1,9 \mathrm{~b}$ & - & - \\
\hline F (trat.) & $0,3 \mathrm{~b}$ & $1,9 \mathrm{~b}$ & $225,79 \mathrm{~b}$ & 225,79 \\
CV (\%) & $101,6^{*}$ & $89,3^{*}$ & $167,5^{*}$ & - \\
\hline
\end{tabular}

Médias seguidas das mesmas letras não diferem entre si pelo teste de Tukey ao nível de 5\%. *: Significativo a 5\%. 
Quadro 3. Porcentagem ${ }^{(1)}$ de frutos perfeitos de atemóia cv. Gefner, nos diferentes tratamentos de polinização. Lins (SP), 2000

\begin{tabular}{lc}
\hline Tratamento & Fruto perfeito $^{(2)}$ \\
\hline 1. Polinização manual (pólen de A. squamosa L.) & $\%$ \\
2. Polinização manual (pólen da mesma cultivar) & $77,6 \mathrm{a}$ \\
3. Polinização manual (pólen da atemóia cV. African Pride) & $21,1 \mathrm{~b}$ \\
4. Polinização manual (pólen da atemóia PR-3) & $33,0 \mathrm{~b}$ \\
5. Polinização natural ou aberta & $9,1 \mathrm{~b}$ \\
F (trat.) & $33,0 \mathrm{~b}$ \\
CV $(\%)$ & $9,4^{*}$ \\
\hline
\end{tabular}

$\left({ }^{1}\right)$ Dados iniciais transformados em arcsen da raiz quadrada de $(x+0,025) .\left(^{2}\right)$ Fruto perfeito: fruto com contornos sem reentrâncias. Médias seguidas das mesmas letras não diferem entre si ao nível de $5 \%$ pelo teste de Tukey. *: Significativo a 5\%.

Quadro 4. Resultados médios dos tratamentos sobre algumas características dos frutos de atemóia cv. Gefner. Lins (SP) 2000.

\begin{tabular}{|c|c|c|c|c|c|c|c|c|}
\hline Tratamento & $\begin{array}{c}\text { Compri- } \\
\text { mento }\end{array}$ & Diâmetro & $\begin{array}{c}\text { Fruto } \\
\text { maduro }\end{array}$ & Casca & Semente & Polpa & Semente & $\begin{array}{c}\text { Sementes por } \\
100 \mathrm{~g} \mathrm{de} \\
\text { polpa }\end{array}$ \\
\hline & $\mathrm{cm}$ & $\mathrm{cm}$ & $\mathrm{g}$ & n. ${ }^{\circ}$ & n. ${ }^{\circ}$ & & & \\
\hline 1. Polinização manual (pólen de A. squamosa L.) & 9,3 & 8,1 & 341,5 & 78,0 & 25,3 & 238,2 & 68,1 & 28,6 \\
\hline 2. Polinização manual (pólen da mesma cultivar) & 8,7 & 7,5 & 235,7 & 58,4 & 12,3 & 164,6 & 37,5 & 22,8 \\
\hline 4. Polinização manual (pólen da atemóia PR-3) & - & - & - & - & - & - & - & - \\
\hline 5. Polinização natural ou aberta & 9,5 & 7,6 & 213,4 & 57,2 & 19,3 & 136,9 & 52,0 & 38,0 \\
\hline
\end{tabular}

Quadro 5. Efeitos dos tratamentos sobre alguns parâmetros dos frutos de atemóia cv. Gefner. Lins (SP), 2000

\begin{tabular}{|c|c|c|c|c|}
\hline Tratamento & $\begin{array}{c}\text { Sólidos } \\
\text { solúveis totais }\end{array}$ & $\begin{array}{c}\text { Acidez } \\
\text { total titulável }\end{array}$ & $\mathrm{pH}$ & SST/ATT \\
\hline & ${ }^{\circ}$ Brix & $\%$ & & \\
\hline 1. Polinização manual (pólen de A. squamosa L.) & 22,3 & 0,60 & 4,65 & 37,2 \\
\hline 2. Polinização manual (pólen da mesma cultivar) & 19,6 & 0,50 & 4,77 & 39,2 \\
\hline 3. Polinização manual (pólen da atemóia cv. African Pride) & 21,4 & 0,43 & 4,79 & 49,8 \\
\hline 4. Polinização manual (pólen da atemóia PR-3) & - & - & - & - \\
\hline 5. Polinização natural ou aberta & 23,8 & 0,54 & 4,72 & 44,1 \\
\hline
\end{tabular}

\section{CONCLUSÕES}

1. Na polinização manual da atemóia, cultivar Gefner, com pólen de diferentes fontes, o da frutado-conde (A. squamosa L.) foi mais efetivo que o da própria cultivar e também que o das atemóias cvs. African Pride e PR-3, aumentando a porcentagem de frutos vingados e a de frutos perfeitos e a de produção total colhida.

2. Quando se comparou a polinização artificial (manual) da atemóia cv. Gefner com a natural, esta foi superada apenas quando se usou o pólen da fruta-doconde; o pólen das outras fontes (atemóias cvs. African Pride e PR-3) mostrou efeito semelhante ao da polinização natural na porcentagem de frutos vingados e de frutos perfeitos e na produção total colhida.

\section{REFERÊNCIAS BIBLIOGRÁFICAS}

CARMO, A.J. Atemóia e pinha vão bem no noroeste de SP. Estado de São Paulo, São Paulo, 10 de maio de 2000. Suplemento Agrícola, n.2322, p.10-11.

DUARTE, O.; ESCOBAR, O. Mejora del cuajado de chirimoya (Annona cherimola Mill.) cv. Cumbe, mediante polinización manual autogama y alogama. Proceedings of the Interamerican Society for Tropical Horticulture, n.41, 162-165, 1997.

DUARTE, O.; PINEDA, A.; RODRIGUEZ, P.P. Mejora del cuajado en atemoya Gefner (Annona squamosa $\mathrm{L}$. $\mathrm{x}$ Annona cherimola Mill.) con diversos tratamientos de polinización manual. Proceedings of the Interamerican Society for Tropical Horticulture, n.43, 1999. 
FARRÉ, J.M.; HERMOSO, J.M. El chirimoyo (Annona cherimola Mill.) en España. In: SÃO JOSÉ, A.R.; SOUZA, I.V.B.; MORAIS, O.M.; REBOUÇAS, T.N.H. (Eds.). Anonáceas, Produção e Mercado (Pinha, Graviola, Atemóia e Cherimólia). Vitória da Conquista: DFZ/ UESB, 1997, p.84-87.

GARDIAZABAL, F.I.; ROSENBERG, G.M. El cultivo del chirimoyo. Valparaíso: Ediciones Universitarias de Valparaíso, 1993. 145p.

GEORGE, A.P.; BROADLEY, R.J. Estrategias de mejoramiento para atemoya y chirimoya. Acta Horticulturae, Wageningen, n.497, p.261-267, 1999.

GEORGE, A.P.; NISSEN, R.J.; BROADLEY, R.J.; ZILL, G. A description of Australian atemoya cultivars. In: CONGRESO INTERNACIONAL DE ANONÁCEAS, 1, 1997, Chapingo, México. Memorias... Chapingo: Universidad Autónoma de Chapingo, 1997. p.153-156.

GUIRADO, E. Polinización artificial del chirimoyo. Caja Rural de Granada, 1992, 15p.
KAVATI, R. O cultivo da atemóia. In: DONADIO, L.C.; MARTINS, A.B.G.; VALENTE, J.P. (Eds.) Fruticultura tropical. Jaboticabal: Funep, 1992, p.39-70.

KAVATI, R.; BUENO, S.C.S.; TOKUNAGA, T.; NOGUEIRA, E.M.C.; TAKASSAKI, J.; PERIOTO, N.W. A Cultura da Atemóia. Campinas: CATI/DSMM, 1997. 22p.

RICHARDSON, A.C.; ANDERSON, P.A. Hand pollination effects on the set and development of cherimoya (Annona cherimola Mill.) fruit in a humid climate. Scientia Horticulturae, Amsterdam, v.65, p.273-281, 1996.

SCHELDEMAN, X.; VAN DAMME, P. Accesiones promisorias de chirimoya en la provincia de Loja, sur del Ecuador. Acta Horticulturae, Wageningen, n.497, p.181-188, 1999.

TOKUNAGA, T. A Cultura da Atemóia. Campinas: CATI, 2000. 80p. (Boletim Técnico, 233) 